\title{
ALHAMBRAS DE IDENTIDAD: MEMORIA DE ESPAÑA EN LA ARQUITECTURA DE PUERTO RICO EN EL SIGLO XX
}

\author{
Alhambras of identity: memoirs of Spain in the Puerto Rico \\ architecture in the 20 century
}

\author{
Silvia Álvarez Curbelo \\ Universidad de Puerto Rico (Puerto Rico)
}

El ensayo interpreta la popularidad de estilos arquitectónicos ligados a lo español en Puerto Rico, la última colonia que tuvo España en el Nuevo Mundo, en las décadas de los años veinte y treinta. A pesar de los relevos culturales que experimentó la isla al convertirse en colonia de Estados Unidos como resultado de la Guerra Hispanoamericana, las ataduras simbólicas con España se ponen de relieve desde dos pulsiones: la moda y la búsqueda identitaria. Lo «español» en la arquitectura, la literatura, el cine toma la forma de revivals desde finales del siglo XIX en Estados Unidos, teniendo como sedes principales a Florida y a California. Por otro lado, el dominio de Estados Unidos sobre Puerto Rico complejiza el tema de la identidad colectiva en un país con una cultura de raigambre y espesores ligados aún a España. La arquitectura es una arena privilegiada para analizar prácticas de significación en las que la modernidad y la tradición exponen sus fortalezas respectivas. Edificaciones públicas y privadas en Puerto Rico adoptan motivos moriscos o del Renacimiento español. ¿Moda, propuesta identitaria o un acomodo negociado entre dos poderosas energías culturales?

Pallabras clave

Arquitectura hispanófila, revival, Puerto Rico, identidad cultural, moda
The essay examines the popularity enjoyed during the 1920's and 1930's by architectural styles reminiscent of Spain in Puerto Rico, the last colony of the Spanish empire in the New World. Notwithstanding the cultural transformations withstood by the island due to the American occupation that began in 1898, the symbolic linkages with Spain gain in relevance through two mechanisms: fashion and the quest of national identity by the Puerto Ricans. "Spanish» revival styles in architecture, literature, films originate mainly in Florida and California but become a worldwide phenomenon. On the other hand, American occupation of Puerto Rico puts the identity theme in the forefront of public debate in a country with a strong Hispanic background. Architecture becomes a privileged site to examine signifying practices in which modernity and tradition expose their respective strengths. Public buildings and private residences were built during this period in Moorish or Spanish Renaissance styles. Fashion or identity proposal or a negotiated cohabitation between two powerful cultural engines?

Keywords

Spanish revival, architecture, Puerto Rico, cultural identity, fashion 
La arquitectura es la expresión del propio ser de las sociedades como la fisonomía humana es la expresión del ser de los individuos.

George Bataille

Las memorias no tienen movimiento. Mientras más ancladas estén en el espacio, más profundas son.

Gastón Bachelard

¿Por qué, Granada bella

bajo tu sol ardiente,

hasta mi cuna olvido

para cantarte a ti?

¿Qué busca en ti mi mente?

¿Qué busca mi mirada

cuando las ruinas toco

de tu pasado ser,

cuando la hiedra arranco

en losas con relieves y fechas del ayer?

Luis Llorens Torres

Hispanofilia: La vuelta imaginaria

En 1899, apenas un año después de la invasión de Estados Unidos a Puerto Rico, un joven abogado puertorriqueño escribió su primer libro de poesía al pie de la Alhambra granadina.

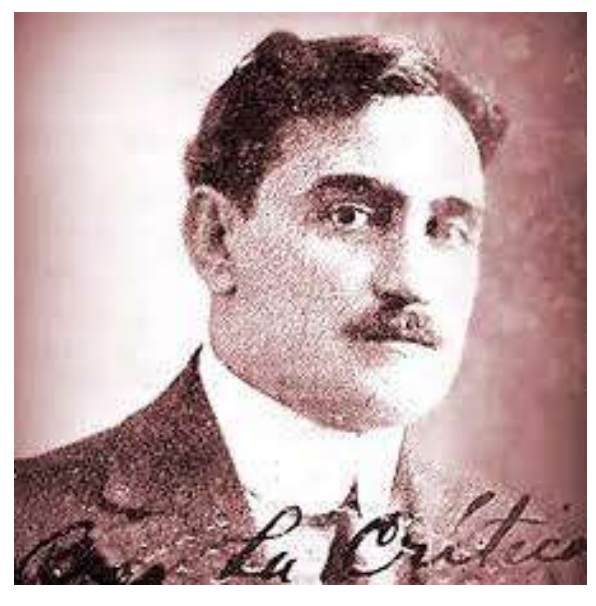

Figura 1. El poeta puer

Así-Al pie de la Alhambra- tituló su poemario (Llorens Torres, 1968). Para una de sus mejores estudiosas, el autor se cuestiona qué es lo que busca su mirada no cuando mira, sino cuando toca las ruinas del «pasado ser» granadino: Las ruinas pasan a ser esos signos de una nueva
ausencia que se hace presente a través de la palabra poética. Si anteriormente la patria era recuerdo siendo olvido, y era presencia reconociéndose ausencia, las ruinas significan ahora las «fechas del ayer», los siglos de vida y de abandono que, a su pesar, permanecen. La sensibilidad de Llorens no me melancolí que se hace cuerpo en las ruinas de la Alhambra. (Rivera, 2014, p. 179).

Eran tiempos de tránsito vertiginoso tras el fin de más de cuatrocientos años de un Puerto Rico español, donde se sucedian otras ruinas (véase figura 2).

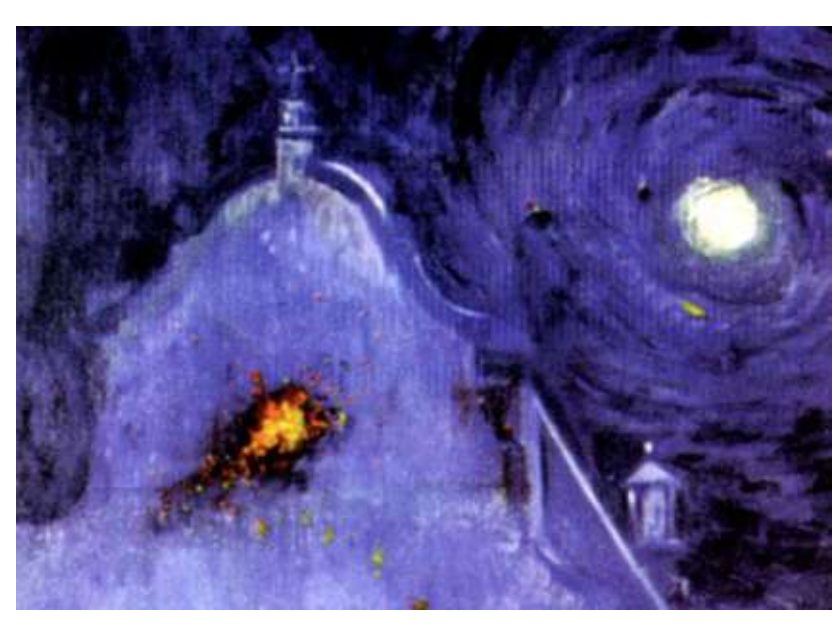

Figura 2. La iglesia des
bardeada en 1898 .

También eran tiempos de ambigüedad e ironía como suelen ser los ocasos imperiales. Cuando los ultimos soldados españoles abandonaron San Juan, lo hicieron desde el mismo lugar (véase figura 3) en que cientos de puertorriqueños le habian dado la bienvenida a la infanta Eulalia de Borbón, de camino a la Exposición Colombina de Chicago, en mayo de 1893 (Álvarez Curbelo, 1997).

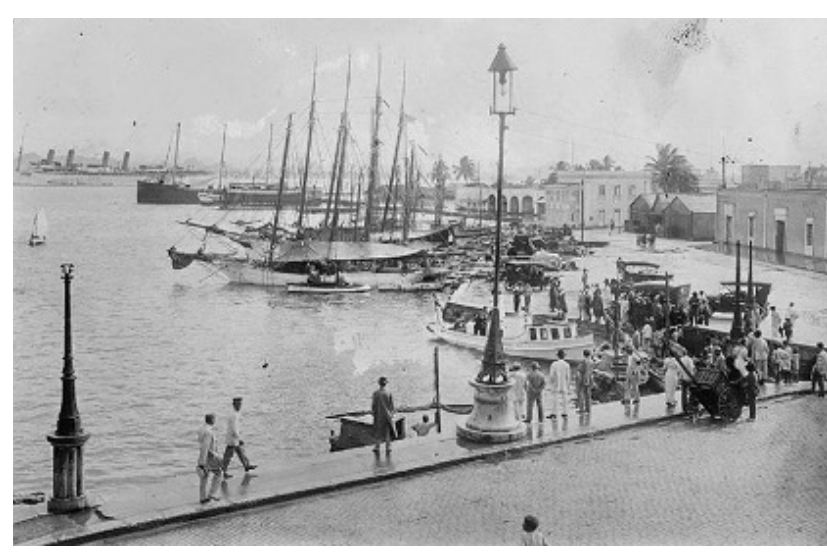

Figura 3. La Dársena, en San Juan (Puerto Rico).
Nunca habíamos sido tan españoles como en aquel momento. En honor a la princesa se habían inaugurado las nuevas obras en los muelles y se había instalado el alumbrado eléctrico en algunas calles de la capital. Aunque debemos señalar que, un año después de la visita real, airados sanjuaneros la incontrolable de precios en las subsistencias populares (Álvarez Curbelo, 1989).

En el discurso de honor al cumplirse los cuatrocientos años del descubrimiento de Puerto Rico, historiador y periodista Salvador Brau cantó a la fecha gloriosa «que marca el feliz momento en que $\mathrm{Bo}$ rinquén es arrebatada a las tenebrosas tinieblas de barbarie para ser entregada en brazos de la civilización redentora» (La llustración Puertorriqueña, 1893). Serían los periodistas criollos, sector que constituyo la vanguardia liberal y modernizadora en las últimas décadas del siglo XIX y que había recibido los golpes de la represión y la censura en fechas tan recientes como 1887, quienes encabezaran la suscripción popular para erigir una estatua al almirante Cristóbal Colón en la plaza frente al Teatro Municipal de San Juan, donde aún está (véase figura 4).

\section{Eadilustracion

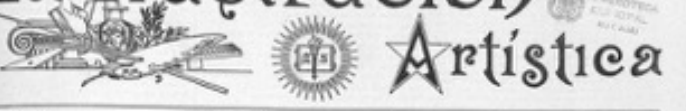

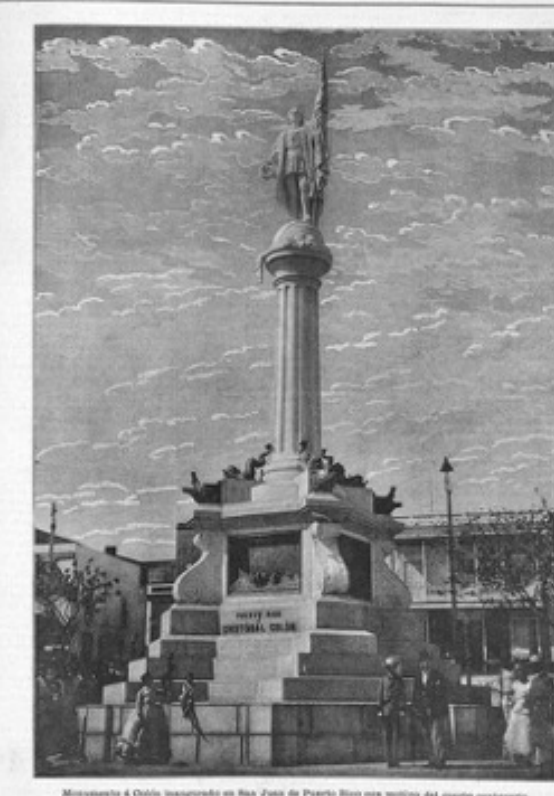

Figura 4. Estatua de Cristóbal Colón en San Juan (Puerto Rico).

El fervor ritualista persistió a lo largo de la década. En 1897, se celebró con galas y festejos popu- lares el primer centenario de la exitosa defensa de San Juan frente las fuerzas británicas. En espera de la concesión de la ansiada autonomía, que habría de llegar en noviembre de ese año, los arrebatos patrióticos nos llevaron a equiparar nuestra repulsa a los ingleses con Sagunto y otras victorias de las armas hispánicas. Durante casi toda su vida como colonia, Puerto Rico había sido el reverso del Eros imperial, pero en 1897 pensamos que por fin Espaen razón viendo arder Cuba.

En el «mundo al revés» que fueron los últimos tiempos de la soberanía española en el Nuevo Mundo, a Puerto Rico le tocó despedir a España. A pesar de su brevedad y la poca complejidad del escenario militar, la guerra y esa despedida condensaron los signos más poderosos de una relación secularmente deficitaria que había creado lazos entrañables y

Cayetano Coll y Toste, entonces subsecretario de Agricultura, Industria y Comercio del gobierno autonómico y que en 1899 asumiría el cargo de secretario civil en la nueva administración, recalaría años mas tarde en la esencial imprecisión del momento. Para él, muchas de las decisiones que los puertorriqueños tomaron entonces fueron producto de pugnas soterradas entre cerebro y corazón, entre los amores, los resentimientos y las esperanzas que convergieron en aquel verano de 1898 :

Si mi cabeza me explicaba a satisfacción el suceso, el corazon, empero, estaba triste [...]. Era el postrer adiós a la querida bandera de nuestros padres y de nuestros abuelos. Fue cruel con nosotros, inconscientemente nos flagelaron el rostro con ella muchas veces injustamente [...] y a pesar de todo,
la amábamos. (Coll y Toste, 1974, pp. 81-82).

Ya de regreso a Puerto Rico y tras ejercer como politico en el nuevo entramado de partidos, la ocupación norteamericana desató en el escritor y abogado Llorens Torres una poética extraordinaria en la que la hispanofilia operaria como una contramitología frente a la pujanza del nuevo imperio que habia hecho retroceder los derechos polticos y el autogobierno concedido por la Carta Autonómica de 1897. Su recuperación filal de Espana se inscribió en un potente discurso de binarismo cultural articulado por el uruguayo José Enrique Rodó en los albores del siglo XX. El arielismo arropó América Latina con su sencilla ecuación. el espintu les pertenece a los pueblos de raizlatina, a los anglosajones les caracteriza el materialismo. En sus poemas de talante épico, Llorens Torres canta a la España de las carabelas mientras parodia la cultura imperialista y crematistica norteamericana. Pero no ocluye la voz propia y mestiza, que expresa mediante criollismos que recuperaban las metricas campesinas ligadas a la cultura popular española. 
La España imaginaria que desplegaría en su escritura no abrevaba en el pasado colonial, injusto y a menudo doloroso. Más bien, en el pasado del revival, un pasado de tiempo suspendido en el que ruinas como la Alhambra de su poemario juvenil suscitaban una «melancolía sublime» (Rivera, 2014 p. 17tentidad y la memoria también es inherente a muchas reflexiones sobre arquitectura. Esta presentación recala en el esencial maridaje entre la arquitectura en Puerto Rico y los dilemas de la identidad en tiempos de relevo colonial, complejizados por en nueva cultura de masas signada por la moda.

\section{La hispanofilia como arquitectura imperial}

En el último tercio del siglo XIX, Estados Unidos, ávido de sumar estirpes para su frágil identidad nacional, incorporó a su genealogía un hispanismo híbriimaginarios de las misiones y la hacienda) con imaginarios épicos de la España peninsular. Templar las "cuerdas místicas de la memoria» (Kammen, 1991) para perfilar una España de uso propio mientras avanzaba ambiciones hegemónicas sobre América Latina y sobre las dos colonias españolas en América fue un proceso que le tomó a Estados Unidos casi todo el siglo.

La Exposición Colombina (véase figura 5), a la que asistió la infanta Eulalia, le dio un imprimátur irónico a dicho proceso de apropiación cultural. Cinco años después estallaría la Guerra Hispanoamericana, que culminó con la expulsión de la soberanía española en tierras americanas.

Pero la distinción simbólica de la Exposición Colombina y otras exposiciones en Estados Unidos a comienzos del siglo XX estriba en que tuvo otras racionalidades que la de legitimar un imperio. En función de los universos del consumo y el entretenimiento, ávidos siempre de novedades, se popularizo una opulenta arquitectura hispanófila de grandes residencias, hoteles, instituciones educativas, hospitales y cines, especialmente pero no limitada a Florida y California, apoyada por prácticas modernas de construcción y ornamentación.

La combinación de inventarios materiales y tecnológicos modernos y el guiño a un pasado patrimonial «hispánico» se presentó en el diseño y construcción de las edificaciones públicas en los primeros tiempos de la dominación norteamericana de Puerto Rico. Para Estados Unidos, su primera experiencia colonial, fuera de la expansión territorial del XIX en territorios contiguos, supuso disyuntivas profundas de traducción -política, lingüistica, legal y cultural-. Puerto Rico y las Filipinas fueron

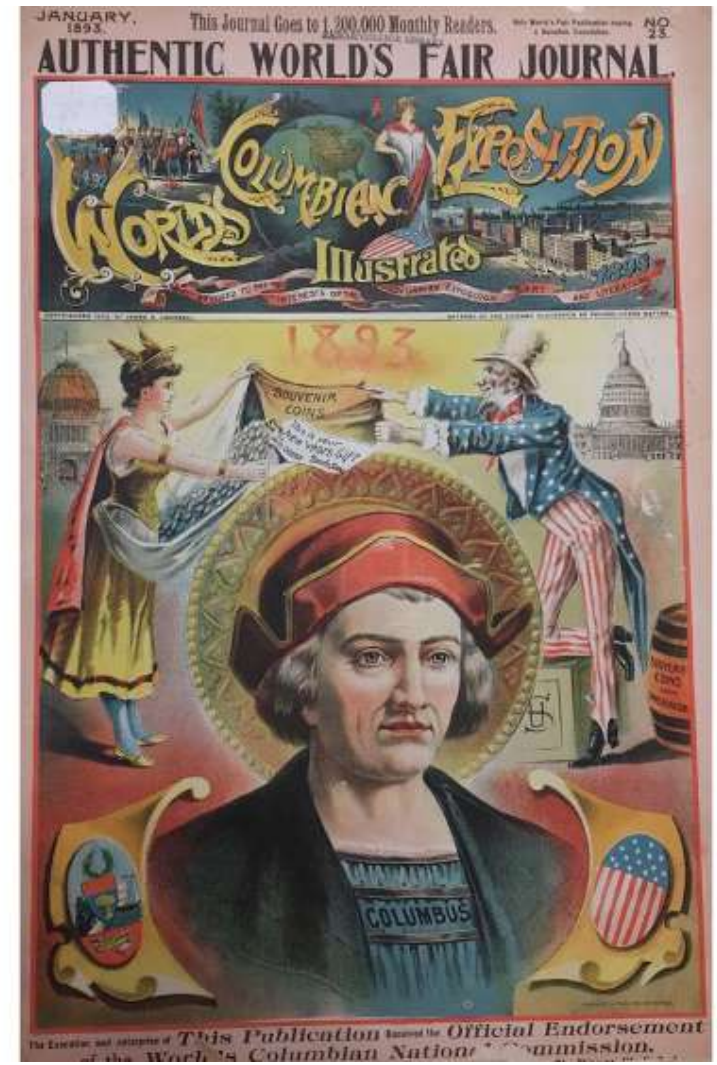

Figura 5. Catálogo de la Exposición Colombina de Chicago.

un imperio y cómo manejar a pueblos de otra ex tracción cultural en los mismos momentos en que buscaban la cifra íntima de su identidad nacional. ¿Con qué codificaciones se trabajan en Puerto Rico las primeras construcciones bajo la nueva dominación, sobre todo las escuelas, las iglesias protestantes y hospitales, símbolos político-culturales por excelencia? En una cortisima primera instancia, con estilos que podemos denominar «federales propios de casas de gobierno e instituciones en Estados Unidos. Pero la atmosfera cultural y estilistica del nuevo gobierno se decantó muy pronto hacia tipologias de revival que parecian entroncar con idiosincrasia fronteriza de Puerto Rico (Vivoni Farage, 1998, p. 124

¿Que más adecuado que el estilo de las misiones californianas, con toques religiosos, para crear escenarios de domesticación en poblaciones de raigambre católica? En un salto mortal geográfico y cultura se homogeneizan -por firmas de arquitectos que en su mayoría operan desde ciudades del este de Estados Unidos- los descendientes novohispanos de California y el suroeste de Estados Unidos con los puertorriqueños en el Caribe. La Escuela Pública N. ${ }^{\circ}$, a la entrada de San Juan, que condensa propuestas de aculturación lingüística, cultural y de laicismo (véase figura 6), y el Hospital Presbiteriano, que conjuga discursos de moral e higiene puritanos y modernos, se edifican en el envoltorio suavemene ondulado, casi infantil, del estilo de las misiones. Cuando se funda la primera universidad en Puerto Rico en el año 1903, una de sus primeras estructuras es la Lechería, cuyo bucolismo misionero se adecua a la misión (valga la redundancia) que le habín asignado a la universidad como capacita habian

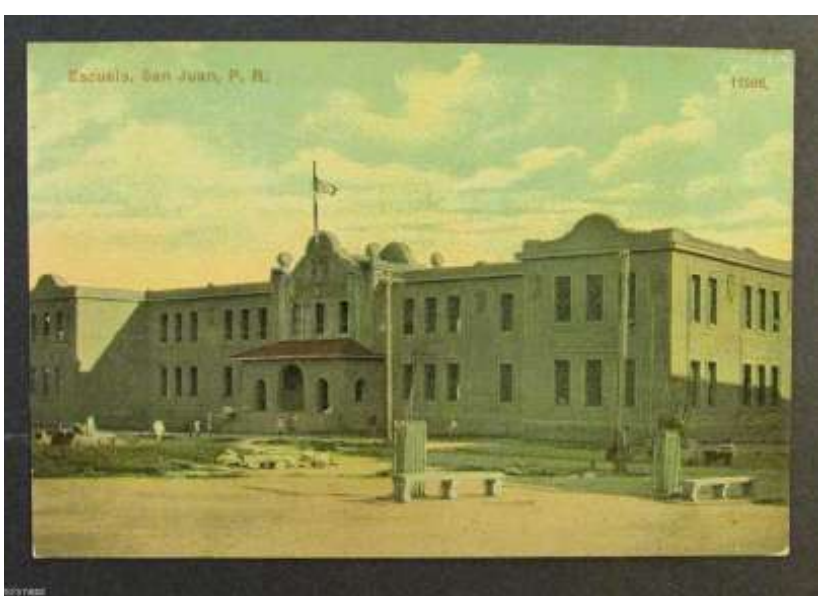

Figura 6. La Escuela Pública N. ำ, en San Juan (Puerto Rico).

Otros revivals, como el neogótico, se colaron en el repertorio de la arquitectura pública e institucional, pero serían los estilos de renacimiento españo y los eclécticos estilos mediterráneos los que finalmente se impondrían como marca. En su popularidad vuelve a jugar un rol significativo otra feria, esta vez la panamericana de San Diego en 1915 (véase figura 7). La teatralidad de la feria se imbricaba esta vez con el novel discurso político del panamericanismo (forma que adopta la emergente hegemoní norteamericana en el hemisferio) para identificar la arquitectura colonial idónea.

Al finalizar la Primera Guerra Mundial, se estimuló una relativa, aunque desfasada, prosperidad en Puerto Rico. Debido a los altos precios cotizados por el azúcar, el pais vivió una breve «danza de los millones» que permitio mayores niveles de gasto público. Igualmente, se animó el gasto privado, especialmente dentro de los sectores afluentes de pais y algunos sectores medios emergentes. Much de este gasto se vertio en el consumo de bienes durables, como automóviles y electrodomésticos, en construcciones de residencias, negocios, sedes cívicas y de entretenimiento (Álvarez Curbelo, 2000 p. 238).

En un momento donde se acentuaba un capitalismo frenético de millonarios instantáneos y rudo que construían castillos como Saint Simeon, la arqu tectura en Puerto Rico acogió también los reclamos de una cultura en alzada que compraba pasados

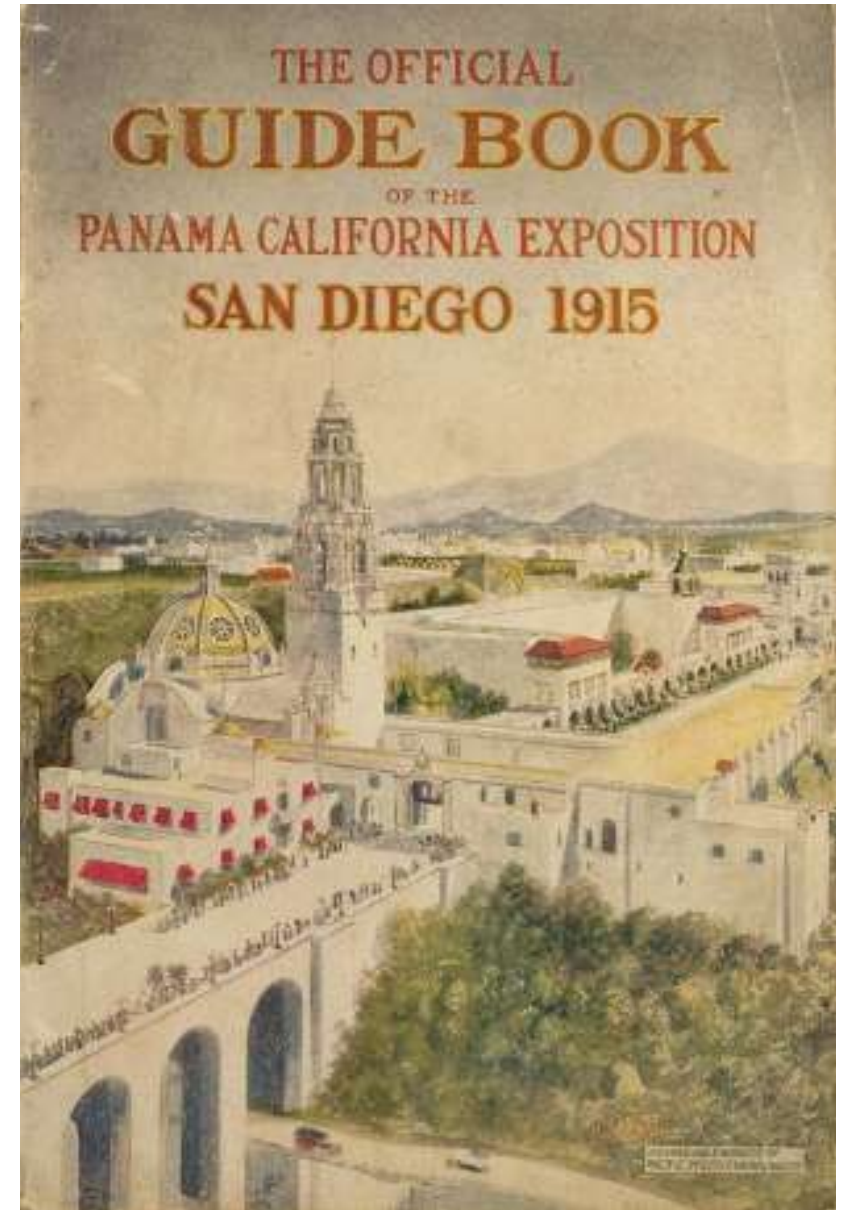

Figura 7. Catálogo de la Exposición Panamericana de San Diego (1915).

elaboraba formas de la memoria como las fantasias de Hollywood. Fortunas deslumbradas por los estilos mediterráneos de Palm Beach y Boca Ratón en Florida; nuevos profesionales recién mudados a Miramar o el Condado, los primeros ensanches en una ciudad hasta hace poco murada, organizaron su gusto desde las revistas, periodicos y películas en búsqueda de la ansiada movilidad social. El auge en la construcción coincidió con la aparición de la primera generación de arquitectos puertorriqueños educada en universidades de Estados Unidos, que transformaron tanto los parámetros de la profesión como la escena arquitectónica insular ( $\mathrm{Vi}$ voni Farage, 1998, p. 126).

\section{La hispanofilia como discurso del subalterno:}

\section{moda y memoria}

Pedro de Castro fue uno de esos jóvenes arquitectos con formación norteamericana cautivados por la nueva escena arquitectónica, fluida y atrevida. En pocos años se convertirá en el arquitecto de moda en Puerto Rico. Con sus fachadas hispanófilas, sus 

ornamentaciones moriscas y sus interiores tec-
nológica y espacialmente modernos, expresó las opacidades de la arquitectura que fungió simultáneamente como moda y representación de idenidad en las décadas iniciales de la nueva soberanía. Pedro de Castro conforma una ciudad de papel. a Pedro de Castro conforma una ciudad de papel; una ciudad contorneada del Caribe, una ciudad ciudad colonial en todo tiempo, si seguimos la intuición de Alejo Carpentier. Sede del artificio, del ornamento, de la inestabilidad, la ciudad barroca se despliega en asimetrías. Como espacio de representación, está sujeta a fuerzas que la doblepan, la pliegan, como si fuera un espacio elástico. Por ello le son tan afines el disimulo y la pretensión pulsiones también de la cultura del entretenimiento y el consumo.

Ocupar esa ciudad no le fue difícil a De Castro, a quien le encantaban el carnaval, la bohemia, el cine, el rizo, en lugar de la línea. Enrique Vivoni Farage, su biógrafo e intérprete por excelencia, ha seguido ese itinerario que en ocasiones parece el de una lentejuelada crónica social hasta el momento mismo de la muerte espectacular del arquitecto (Vivoni Farage, 1999, pp. 102-104). La teatralización de los diseños y su puesta en escena es una vocación que Vivoni Farage advierte en De Castro desde su entrenamiento en la Universidad de Syracuse.

El carnaval fue un referente constante en la vida y la práctica del arquitecto De Castro: fabrica escenografías, diseña vestuarios y programas para las carnestolendas. Quizás su carnaval más elaborado fue la inauguración de su propia casa (véase figura 8). Desde el emplazamiento, el escudo familiar, el lucero que funge como leitmotiv decorativo y enseña, Casa Andalucía fue concebida como una casa para desplegar linaje, para marcar una distinción y fijar un sello desde la ancestralidad de una cultura materna hispanica teatralizada.

De Castro comienza su educación formal al calor de convocatorias disímiles. la incursión deslumbrante de la comunicación de masas mediante el cine, más tarde la radio y las revistas de circulación mundial que fortalece una cultura de futuro cohabita en Puerto Rico con los cantos de duelo por lo perdido: la tierra que se escapa a manos de las corporaciones azucareras, la lengua madre que se prostituye con el lexico invasor, el sino político que se tuerce ante el capricho imperial.

Cuando junto a otro arquitecto, Francisco Roldán, rubrica un diseño para el Capitolio de Puerto Rico, elude los modelos federales obsequiosos, pero también los pretenciosos afrancesamientos favorecidos por cierta elite policica criolla. Selecciona un estilo hispanófilo, no el condescendiente estilo

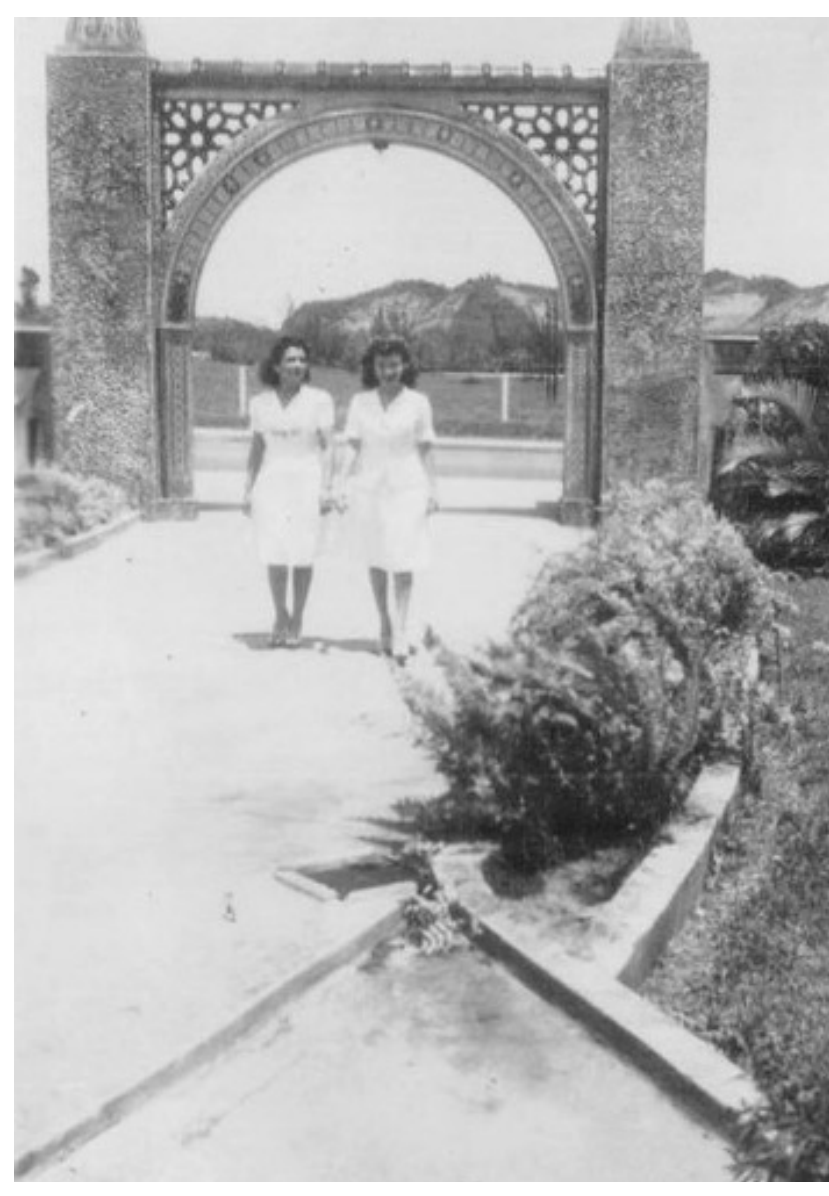

Figura 8. Pórtico de la residencia del arquitecto Pedro de Castro, circa 1940

de las misiones de los administradores coloniales de comienzos de siglo, sino el renacimiento glorioso del imperio de Carlos I y Felipe II. Incongruente, ironico, oportunista, el revival hispanófilo es su carta de independencia profesional. De Castro anticipa con exito comercial y estético una España indispensable en nuestros tránsitos coloniales. Con pleno ademán barroco, De Castro arma su repertorio hispanófilo mediante dos estrategias de manejo del pasado: en ocasiones, lo desestabiliza para interpretar el presente, como ocurre con los diseños en que combina la hispanofilia con el art déco para sus edificios de cine, el cine Rialto y el cine Tres Banderas; en otras, lo estabiliza para evocar modelos y valores para transitar los tiempos que vive. Es el caso de su diseño para la Casa de España (véase figura 9).

En De Castro la hispanofilia es primor, capricho, insinuación, amor perdido y vuelto a ganar, en medio de los nuevos e indiscutidos amos. Al lado de la ciudad norteamericanizada de la que no rehúye que acoge en sus interiores modernizados, levanta una ciudad paralela, fantasmagórica y misteriosa, cual truco del subalterno, que la contrapesa.

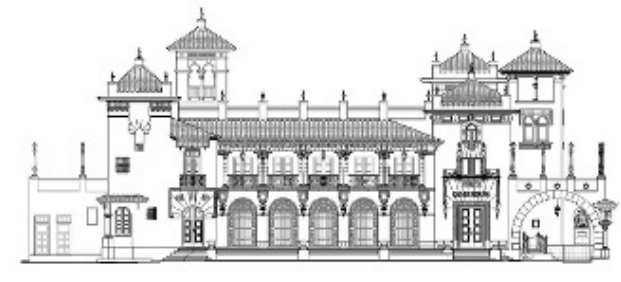

Figura 9. Casa de España en San Juan (Puerto Rico).

La hispanofilia de Palm Beach: el nudo de la moda

España, otrora enemiga de guerra, conquista en los años veinte la imaginación de Hollywood (véase figura 10).

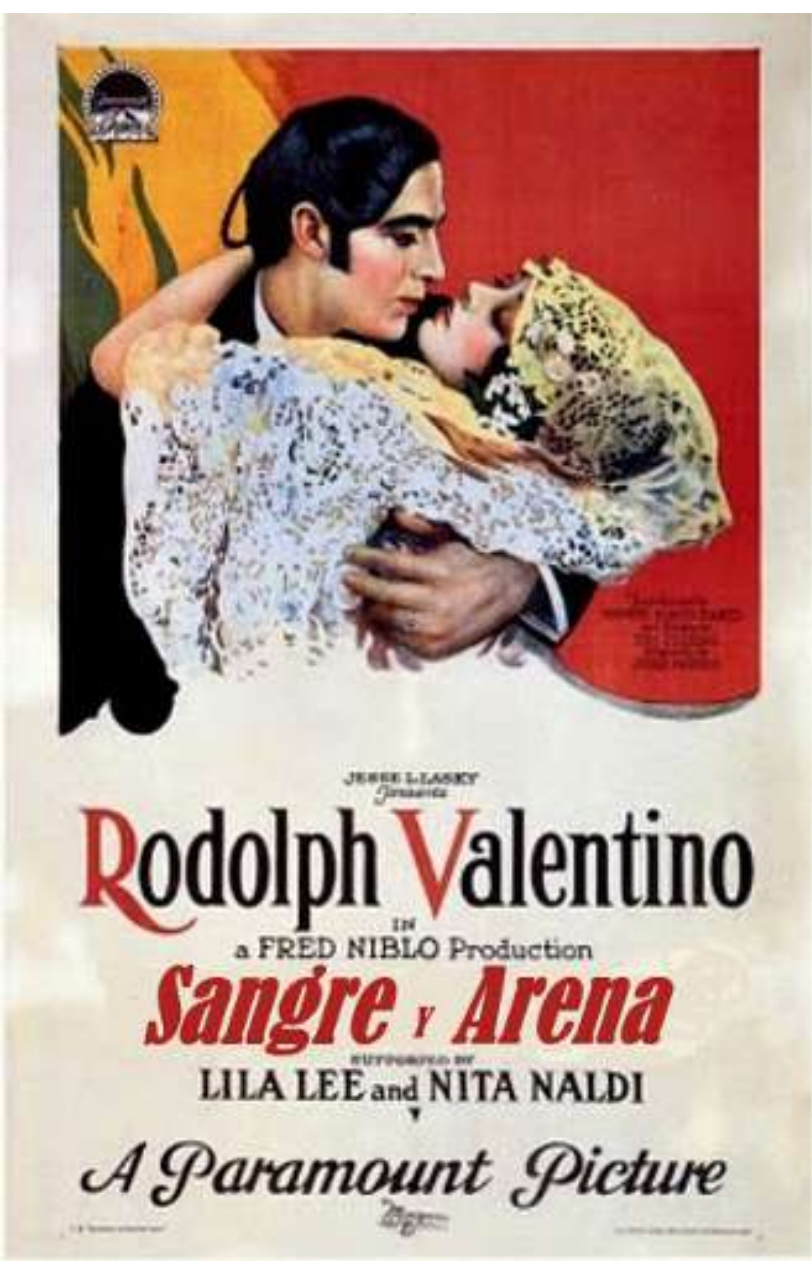

Figura 10. Fiebre hispanófila en Hollywood.

Ídolos de la pantalla como Rodolfo Valentino Ramón Novarro y Lupe Vélez interpretan personajes que evocan una España legendaria y exótica. En el sureste de la Florida, el arquitecto Addison Mizner perpetúa en residencias y clubes privados de Palm Beach y Boca Ratón una arquitectura que integra elementos moriscos y renacentistas españoles en un ecléctico estilo mediterráneo (véase figura 11).

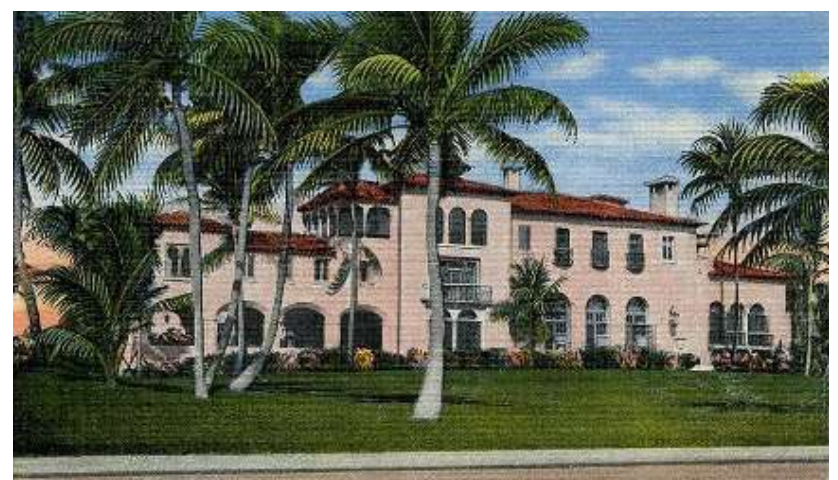

Figura 11.
Mizner).

Una España espectacularizada es la anfitriona en 1929 de la Exposición Iberoamericana celebrada en Sevilla, que renueva la hermandad entre España y los pueblos de América (véase figura 12).

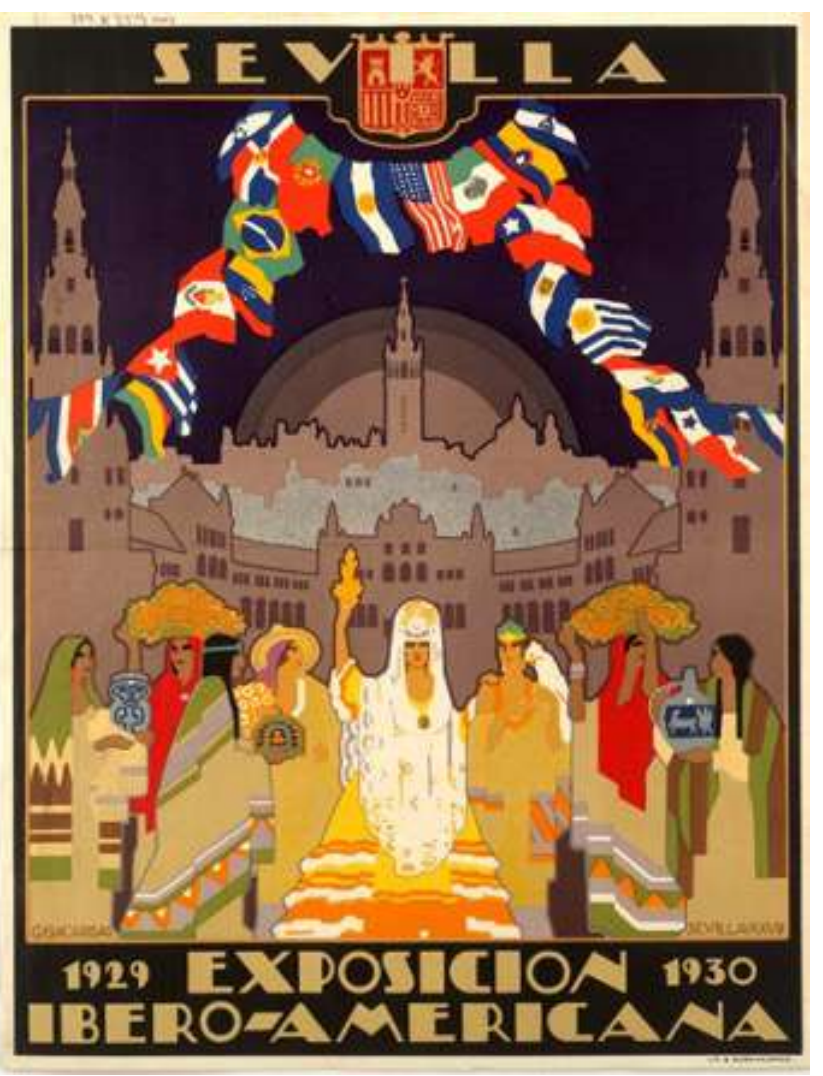

Figura 12. Póster de la Exposición lberoamericana (1929-1930). 
El revival del renacimiento español en la Florida, nos señala Rafael Crespo, se percibió por arquitectos puertorriqueños como De Castro y Rafael Carmoega, entre otros, como el lenguaje perfecto para la nueva arquitectura puertorriqueña (Crespo, 1998, p. 76). Era lo suficientemente familiar con el pasado reciente del país como para no crear un shock cultural y lo suficientemente moderno como para quedar legitimado por el fenómeno ya omnipresente de la moda. Para Crespo, era también un estilo adaptable a muchos tipos de construcción.

De ahí que en Puerto Rico se recurriera a él en las décadas de los veinte y los treinta para edificar el complejo central de la Universidad de Puerto Rico; sedes civicas como el Ateneo Puertorriqueño, el Instituto de Medicina Tropical, el Hospital de Psiquiatría: casas en las primeras comunidades suburbanas y en las prepotentes casas de las fortunas azucareras, cuyos dueños, para colmo de las ironías culturales, eran políticamente favorecedores de la anexión plena del país a Estados Unidos.

Los castillos que De Castro diseñó para dos de las fortunas azucareras más acaudaladas de Puerto Rico constituyen ejemplos perfectos de una casa de ostentación, erigida, entre otras cosas, como propuesta de poder de sus dueños. En plena Gran Depresión, mientras los precios del azúcar descendían de manera estrepitosa y la economía de enclave entraba en franca crisis, se alzaron dos estructuras en estilo hispanófilo en una misma ciudad de Puerto Rico: Ponce, sede principal de la industria. Ambas familias se identificaban en términos políticos con la anexión de la isla a Estados Unidos, pero su opción estilística se alineó con la vieja metrópolis. Por el lado de la moda, De Castro garantizó a sus clientes los parámetros establecidos por Mizner y otros en la Florida; por el lado identitario, sus diseños se nutrieron de la familiaridad con los simbolos hispánicos a pocas décadas del pasado colonial con sus referentes culturales y de estratificacion social profundos.

En el Castillo Serrallés, la hispanofilia se decantó por una Espana de reconquista más dura; en la otra, España, atravesada por lo morisco, se presentaba en graciosos patios interiores y torres andaluzas. Las dos fueron casas teatralizadas: la de la familia
Serrallés domina, desde su emplazamiento, una vista panorámica de la ciudad, que se posa a sus pies (véase figura 13).

En el diseño para la familia Cabassa, la casa discurre a lo largo y ancho de una manzana completa de terreno y se distingue por su volumetría de las casas circundantes, propiedad de sus competidores en el negocio azucarero (vease figura 14).

El arquitecto y sus clientes conformaron dos espacios antológicos de figuraciones de identidad

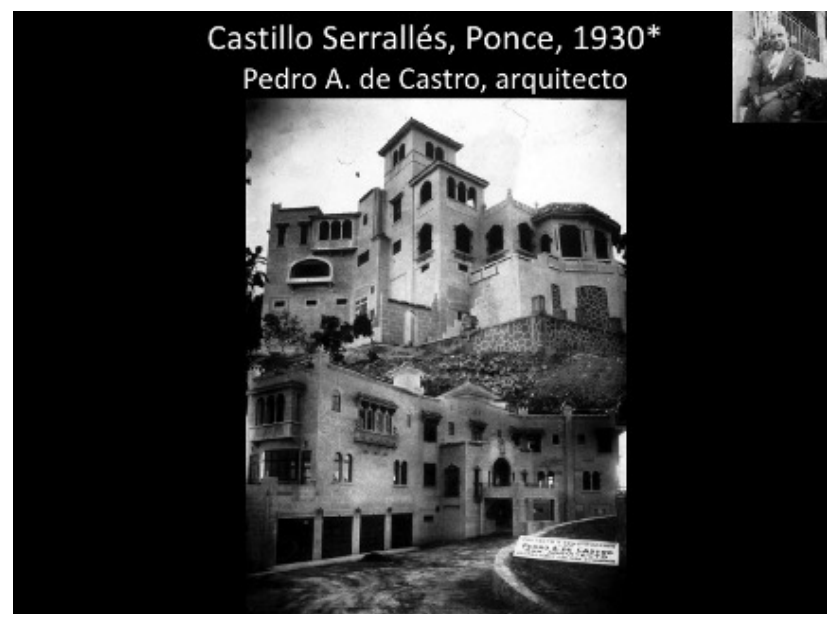

Figura 13. Castillo Serrallés, en Ponce (Puerto Rico).

desde las pulsiones simultáneamente efímeras sublimes, frívolas y poéticas del revival hispanófio. En todo caso, ambas fueron casas de decadencia, en el sentido de que serían culminación y a la representaciones arquitectónicas. Desde sus recién construidos castillos de azúcar, estas familias y con ellas los miembros de su clase y generación vieron desaparecer, en muy corto tiempo, el mundo que habían armado, no sin antes agotar-como en un carnaval- los caprichos del privilegio y de gusto.

Residencia J. Cabassa, Ponce, 1934 Pedro A. de Castro, arquitecto

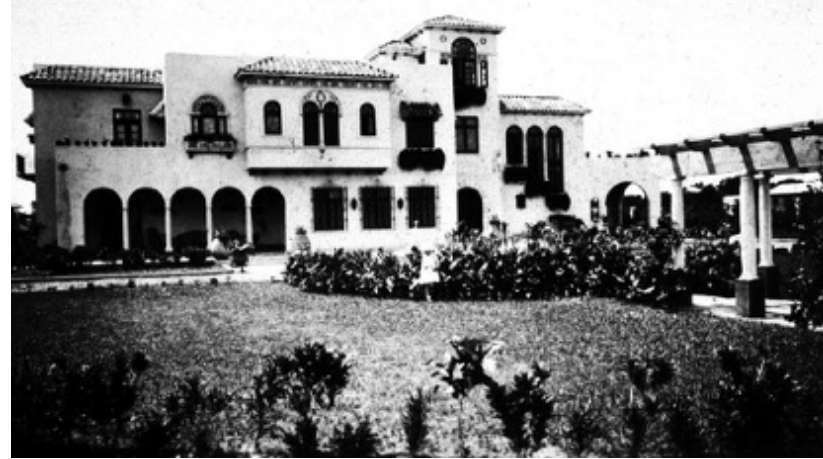

Figura 14. Casa Cabassa, en Ponce (Puerto Rico)

Cuando la guerra volvió a estallar en Europa a finales de los treinta, Puerto Rico despegaba un nuevo proyecto político y económico moderno. Los castillos se cerraron, algunos físicamente, ambos como sedes simbólicas vivas, para reemerger como ruinas precoces y museificables.

\section{Epílogo}

A punto de comenzar el siglo $X X$, el poeta puertoriqueño Luis Llorens Torres le cantó a la ciudad es pañola de Granada con estas palabras: «¿Por qué Granada bella, / bajo tu sol ardiente, / hasta mi cuna olvido / para cantarte a ti?». Desde entonces, las memorias, el idioma, las costumbres y el espaci construido -sea o no en forma de revival- refiere a una España presente en todas nuestras preguntas sobre quiénes somos nosotros, quiénes son lo otros; aunque las respuestas estén salpicadas con las memorias amargas de la esclavitud y el coloniaje. Al avanzar la década de los treinta, abatido e pais por la crisis económica y el desgaste institucional y social, intelectuales, políticos y artistas multiplicaron las búsquedas y las reflexiones en torno a lidentidad, cuáles eran nuestros pasados y cómo serian nuestros destinos. El nacionalismo domino discursos literarios y dio pie a proyectos políticos que endurecieron la hispanofilia más lúdica e irónica de años previos. La España católica, ortodoxa y conquistadora recuperó terreno al calor de la Depresión y el avance del fascismo. Pero, al final, como habia ocurrido apenas dos décadas atrás, la guerra se convirtió en un umbral que dio paso a cambios estilos hispanófilos en la arquitectura fueron relegados en Puerto Rico a favor de estilos modernos y funcionalistas.

Tras la victoria aliada en 1945, los proyectos turisticos y urbanísticos más importantes en el país reflejan la aceptación del Movimiento Moderno y sus valores de libertad, progreso y comodidad (véase figura 15). España parecía entonces demasiado vinculada con el fascismo derrotado para ser un referente aceptable (Torres Santiago, 2000, p. 148). Los

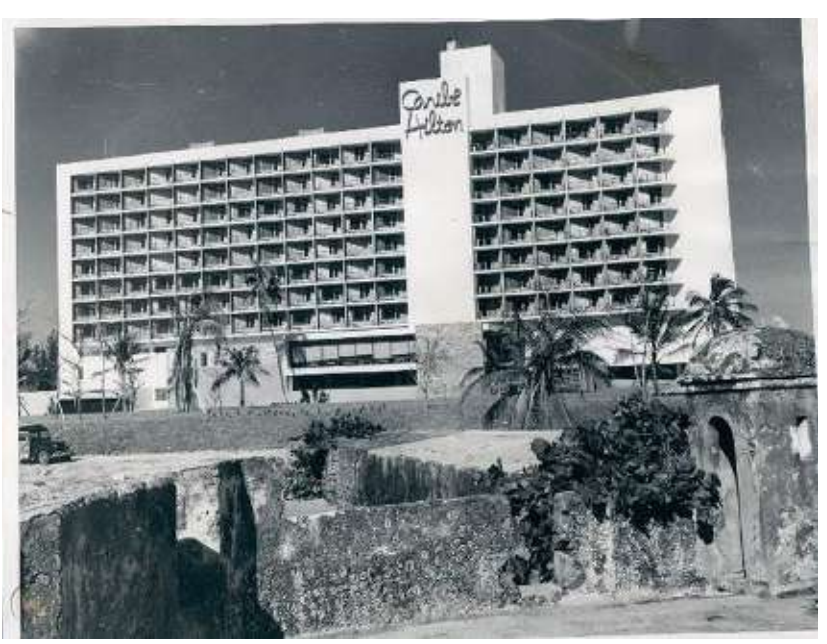
de la isleta de San Juan (Puerto Rico). Las ruinas del Fortín de San Jeronimo, a los pies de la foto. enfoques historicistas que habían dominado en la década anterior quedaron marcados como particularistas y retrógrados. La moda de la arquitectura moderna internacional barrería los revivals y propondría gramáticas de tabula rasa en las edificaciones privadas y públicas.

Pero como la moda y la memoria histórica plantean siempre la oportunidad de una segunda existencia (Baudrillard, 1977), la hispanofilia en Puerto Rico tendría nuevas reencarnaciones en los años subsiguientes, las sigue teniendo; reencarnaciones privadas, reencarnaciones públicas siempre en combinación inestable con otras opciones culturales y politicas de identidad para nuestro país (véase figura 16)

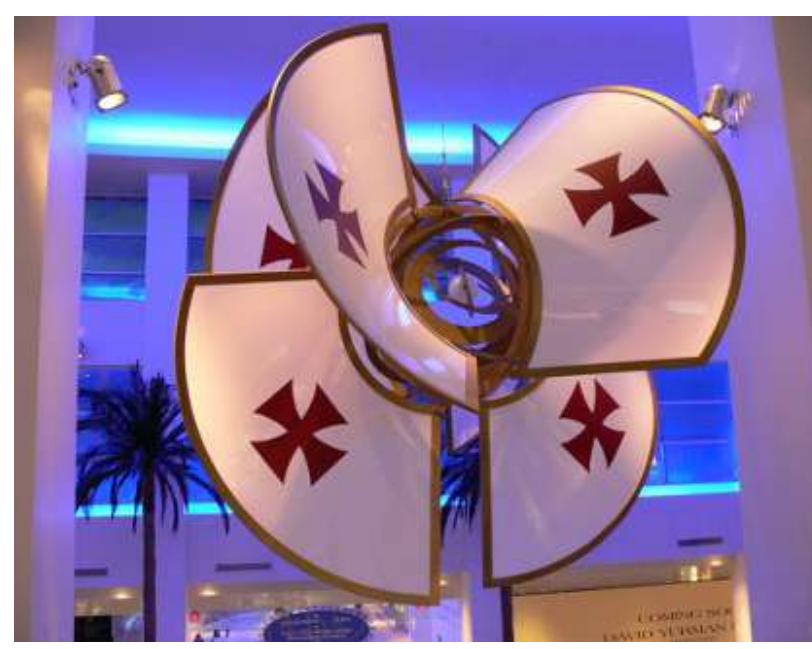

Figura 16. El logo de plaza Las Américas, en San Juan (Puerto colombinas.

Fuentesybibliografía

Álvarez Curbelo, S. (1989): «El motín de los faroles y otras luminosas protestas», en Historia y Sociedad, año $\|_{1}$ pp. $120-146$.

(1997): «Despedidas», en Revista de Indias, vol. LVII (211), pp. 783-799.

ciudady, en Enrique Vodo: arquitectura, consumo y m pre nuevo: arquitectura y modernización en el Baudrillard, J. (1977): El intercambio simbólico y la muerte. Gallimard.

Coll y Toste, C. (1974): La invasión norteamericana en Puerto Rico. J. Mejorada Cejudo.

Crespo, R. A. (1998): «El revival español en Florida», en Hispanofilia: arquitectura y vida en Puerto Rico, 1900 1950, pp. 27-89. Editorial de la Universidad de Puerto Rico.
mmen, M. (1991): Mystic Chords of Memory: The Transformation of Tradition in American Culture. Knopf. 
La llustración Artística, año XIII (647), 21 de mayo de 1894.

La llustración Puertorriqueña, año II, 19 de noviembre de 1893, número extraordinario dedicado a conmemorar el Cuarto Centenario del Descubrimiento de Puerto Rico.

Llorens Torres, L. (1968): «Al pie de la Alhambra», en Obras completas, tomo I. Instituto de Cultura Puertorriqueña.

Moreno, M. L. (2000): La arquitectura de la Universidad de Puerto Rico, Recinto de Río Piedras. Editorial de la Universidad de Puerto Rico.

Rivera, L. (2014): «Luis Llorens Torres, poeta al pie de las ruinas», en Revista de Estudios Hispánicos, I (2), pp. 177-186.

Torres Santiago, J. (2000): «La invención de los umbrales del Edén: imágenes, arquitectura y contexto en el desarrollo hotelero de San Juan», en Enrique Vivoni Farage (ed.): San Juan siempre nuevo: arquitectura y modernización en el siglo XX, pp. 118-167. AACUPR/ Comisión 2000.

Vivoni Farage, E. (1998): «La arquitectura de la identidad puertorriqueña», en Enrique Vivoni Farage y Silvia Álvarez Curbelo (eds.): Hispanofilia: arquitectura y vida en Puerto Rico, 1900-1950, pp. 117-154. Editorial de la Universidad de Puerto Rico.

-(1999): Alarife de sueños: Pedro Adolfo de Castro y Besosa. Archivo de Arquitectura y Construcción de la Universidad de Puerto Rico.

\section{Lista de figuras}

Figura 1. Foto. El poeta Luis Llorens Torres. Cortesía del periódico Claridad, de San Juan (Puerto Rico).

Figura 2. Composición artística realizada en 1999 por el colectivo de investigación CARIMAR, basada en una fotografía de 1898. Cortesía de CARIMAR, de San Juan (Puerto Rico).

Figura 3. Foto. La Dársena, San Juan (Puerto Rico). Fotógrafo Atilio Moscioni, circa 1910. Dominio público. Cortesía del Archivo General de Puerto Rico.

Figura 4. Portada. La llustración Artística, año XIII, 21 de mayo de 1894, núm. 647. Dominio público. Cortesía de Colección Puertorriqueña, Biblioteca General José M. Lázaro, Universidad de Puerto Rico.

Figura 5. Póster. The World's Columbian Exposition Illustrated, núm. 23, enero de 1893. Dominio público. Recuperado el 7 de septiembre de 2020 en http:// pages.vassar.edu/library/2018/04/surveys-and-souve nirs-american-worlds-fairs-1876-1939/3 img 2195 wcei-jan-1893 preview/

Figura 6. Tarjeta postal. La Escuela Pública N. 1, en San Juan (Puerto Rico), en el estilo arquitectónico de las misiones, circa 1910. Recuperada el 11 de junio de 2020 en https://i.ebayimg.com/images/g/jR4AAMXQ VERSty-d/s-11600.jpg

Figura 7. Catálogo. Exposición de San Diego, 1915. Wikimedia Commons. Dominio público. Recuperada el 14 de septiembre de 2020 en https:/lupload.wikimedia. org/wikipedia/commons/2/20/Guide Book of the Panama California Exposition.jpg

Figura 8. Foto. Pórtico de la residencia del arquitecto Pedro de Castro, circa 1940. Cortesía de Puerto Rico Historic Building Drawings Society.

Figura 9. Dibujo. Casa de España, en San Juan (Puerto Rico). Arquitecto: Pedro de Castro. Cortesía de Puerto Rico Historic Building Drawings Society.

Figura 10. Póster. Película Sangre y arena. Wikimedia Commons. Dominio público. Recuperado el 15 de septiembre de 2020 en https://commons.wikimedia. org/wiki/File:Blood and Sand 1922 poster.jpg

Figura 11. Tarjeta postal. Residencia El Mirasol en Palm Beach (Florida), circa 1920. Arquitecto: Addison Mizner. Wikimedia Commons. Dominio público. Recuperada el 12 de junio de 2020 en https:// upload.wikimedia.org/wikipedia/commons/1/1e/El Mirasol\%2C Palm Beach\%2C FL.jpg

Figura 12. Póster. Exposición Iberoamericana, 1929-1930. Wikimedia Commons. Dominio público. Recuperado el 15 de septiembre de 2020 en https://commons. wikimedia.org/wiki/File:Expo sevilla 1929 poster.jpg

Figura 13. Castillo Serrallés, en Ponce (Puerto Rico). Slide Show «La permanencia de lo efímero. Actualidad patrimonial en la arquitectura del siglo XX en el Caribe y Andalucía. Los casos de Puerto Rico y Málaga. Arquitectura del siglo XX de la Isla del Encanto». Sevilla, marzo de 2009. Cortesía del Archivo de Arquitectura y Construcción de la Universidad de Puerto Rico.

Figura 14. Casa Cabassa, en Ponce (Puerto Rico). Slide Show «La permanencia de lo efímero. Actualidad patrimonial en la arquitectura del siglo XX en el Caribe y Andalucía. Los casos de Puerto Rico y Málaga. Arquitectura del siglo XX de la Isla del Encanto». Sevilla, marzo de 2009. Cortesía del Archivo de Arquitectura y Construcción de la Universidad de Puerto Rico.

Figura 15. Foto. Hotel Caribe Hilton en 1950. Dominio público. Recuperada el 12 de junio de 2020 en https:// www.worthpoint.com/worthopedia/1950-caribe-hil ton-san-juan-puerto-108763631

Figura 16. Foto. Logo de plaza Las Américas, en San Juan (Puerto Rico). Recuperada, el 12 de junio de 2020 en https://www.skyscrapercity.com/threads/P.san-juansan-juan-metro-plaza-las-américas. 363797/ 